\title{
Bilateral Uveitis Secondary to Bisphosphonate Therapy
}

\author{
Yar Li Tan Joanne Sims Soon Phaik Chee \\ Singapore National Eye Centre, Singapore, Singapore
}

\section{Key Words}

Uveitis · Bisphosphonates

\begin{abstract}
Background/Aims: To highlight the potential ocular side effects of bisphosphonate therapy and the importance of a proper drug history in patients who present with uveitis. Methods: We report 2 cases of bilateral uveitis secondary to bisphosphonate therapy. Both patients were on nitrogencontaining bisphosphonates when they developed symptoms of bilateral anterior uveitis. A uveitis screen done in both cases was normal. Results: The uveitis in both patients resolved after discontinuation of the bisphosphonates, and there has been no recurrence of symptoms during the duration of the follow-up of 6 and 5 months, respectively. Conclusion: All patients receiving bisphosphonates who develop ocular signs and symptoms should be referred promptly to an ophthalmologist. The offending drug should be discontinued once the diagnosis is made, in order to prevent involvement of the contralateral eye and recurrent or chronic ocular inflammation. Patients who are susceptible to the nitrogen-containing bisphosphonates should be switched to the non-nitrogen-containing bisphosphonates.
\end{abstract}

Copyright $\odot 2009$ S. Karger AG, Basel

\section{Introduction}

Bisphosphonates are considered the treatment of choice for Paget's disease, malignant hypercalcaemia, bone metastases and osteoporosis, as they have a strong anti-osteoclastic activity and are potent inhibitors of bone resorption [1]. Ocular inflammation, including non-specific conjunctivitis, uveitis, episcleritis and scleritis, has been reported secondary to bisphosphonate use but may be underrecognized as a cause of uveitis $[2,3]$. Here we report 2 cases of bilateral uveitis secondary to bisphosphonate therapy.

\section{Case Reports}

Case 1

A 57-year-old Chinese woman developed left eye redness and headache 4 days after being started on alendronate for osteoporosis. Ocular examination showed left anterior uveitis with visual acuity $6 / 9$ and $2+$ cells in the anterior chamber. Fundal examination was unremarkable. Right eye examination was normal. She was started on hourly topical steroid to the left eye and 3 days later was noted to have $1+$ cells present in both eyes. She was then treated with 2-hourly topical steroids to both eyes. A uveitis screen was normal, and the patient discontinued alendronate. One week later the uveitis had resolved in both eyes, and no recurrence developed after tapering the topical steroids. There has been no recurrence of symptoms during the duration of a follow-up of 6 months since discontinuation of the bisphosphonate.

Case 2

An 86-year-old Chinese woman developed bilateral anterior uveitis 8 months after starting bisphosphonate. She received alendronate for 6 months and subsequently was changed to risedronate for 2 months. She had right phaco-emulsification and intraocular lens implantation performed for a visually significant cataract and was first noted to have increasing right anterior uveitis with redness and $3+$ cells in the anterior chamber 5 days after her surgery. Of note, the surgery had been uneventful, no residual lens

\section{KARGER \\ Fax +41613061234 \\ E-Mail karger@karger.ch}

www.karger.com
(C) 2009 S. Karger AG, Basel

0030-3755/09/2233-0215\$26.00/0

Accessible online at:

www.karger.com/oph
Soon Phaik Chee

11 Third Hospital Avenue

Singapore National Eye Centre

Singapore 168751 (Singapore)

Tel. +65 62277 255, Fax +65 62277 290, E-Mail chee.soon.phaik@snec.com.sg 
cortex or nucleus was detected in the anterior chamber, and no deposits were observed on the intra-ocular lens and posterior capsule to suggest an infective cause. The frequency of the topical steroid was increased from 3- to 2-hourly application. Two days later, it was noted that there were $1+$ cells in her fellow eye. She was then also started on topical steroid for her left eye, but lowgrade uveitis persisted for the next 2 months. A uveitis screen was normal and risedronate was discontinued. The uveitis in both eyes resolved within 2 weeks, and the topical steroids were tapered off without any recurrence of symptoms. During a follow-up period of 5 months, there has been no recurrence of ocular inflammation.

\section{Discussion}

Ocular complications secondary to bisphosphonates are rare with incidence ranging from 0.046 to $1 \%$ [4]. Non-specific conjunctivitis, uveitis, episcleritis, scleritis and optic neuritis have all been reported [2-4]. Uveitis can be unilateral or bilateral and has been described up to 1 year after commencing medication $[5,6]$. All known cases of intra-ocular inflammation have involved anterior uveitis without vitreous involvement. Bisphosphonates can be divided into nitrogen-containing and nonnitrogen-containing agents. All known cases have been associated with nitrogen-containing bisphosphonates, most commonly following intravenous palmidronate treatment for Paget's disease and hypercalcaemia [4, 7]. Recurrence of ocular inflammation has been shown to occur with rechallenge $[8,9]$. Alendronate and risedronate, also nitrogen-containing, have been associated with uveitis to a lesser degree [10]. The non-nitrogen-containing bisphosphonates etidronate and clodronate have not been associated with uveitis [3]. Nitrogen-containing bisphosphonates are associated with acute-phase reactions, characterized by transient fever, lymphocytopenia and elevation of C-reactive protein, interleukin 1 and interleukin 6 . However, the reason why the uvea is a target organ is still unclear [2].

With the increasing use of bisphosphonates, it is important for clinicians to be aware of potential ocular side effects and to obtain a proper drug history. First of all, we recommend that all patients receiving bisphosphonates who develop ocular signs and symptoms should be referred promptly to an ophthalmologist. Secondly, once the diagnosis is made, the offending drug should be discontinued in order to prevent involvement of the contralateral eye and recurrent or chronic ocular inflammation. Patients who are susceptible to the nitrogen-containing bisphosphonates should be switched to the non-nitrogencontaining bisphosphonates.

\section{References}

-6 Stack R, Tarr K: Drug-induced optic neuritis and uveitis secondary to bisphosphonates. NZ Med J 2006;119:U1888. pedicine into clinged me practice: comparing anti-resorptive agents for the treatment of osteoporosis. Curr Med Res Opin 2004;20:525-531.

- Moorthy RS, Valluri S, Jampol LM: Druginduced uveitis. Surv Ophthalmol 1998;42: 557-570.

3 Fraunfelder FW, Rosenbaum JT: Drug-induced uveitis: incidence, prevention and treatment. Drug Saf 1997;17:197-207.

4 Macarol V, Fraunfelder FT: Pamidronate disodium and possible ocular adverse drug reactions. Am J Ophthalmol 1994;118:220224.

5 Malik AR, Campbell SH, et al: Bilateral acute anterior uveitis after alendronate. $\mathrm{Br} \mathrm{J} \mathrm{Oph-}$ thalmol 2002;86:1443.
7 Ghose K, Waterworth R, Trolove P, et al: Uveitis associated with pamidronate. Aust NZ J Med 1994;24:320.

8 Asensio Sánchez VM, Botella Oltra G, Carrasco E: Biphosphonates and intraocular inflammation. Arch Soc Esp Oftalmol 2004; 79:85-87.

9 Fraunfelder FW, Fraunfelder FT, Jensvold B: Scleritis and other ocular side effects associated with pamidronate disodium. Am J Ophthalmol 2003;135:219-222.

10 Siris ES: Bisphosphonates and iritis. Lancet 1993;341:436-437. 